Covered in: Web of Sciences (WOS); EBSCO; ERIH+; Google Scholar; Index Copernicus; Ideas RePeC; Econpapers; Socionet; CEEOL; Ulrich ProQuest; Cabell, Journalseek; Scipio; Philpapers; SHERPA/RoMEO repositories; KVK; WorldCat; CrossRef; CrossCheck

2018, Volume 10, Issue 1, pages: 171-182 | doi: https://doi.org/10.18662/rrem/27

\section{Fundamentals of Education in Knowledge Society: Theoretical Forecast}

\author{
Alexander O. KARPOV ${ }^{1}$ \\ ${ }^{1}$ State Center «Interphysica», \\ Moscow, Russia, \\ a.o.karpov@gmail.com
}

\begin{abstract}
This paper studies the problem of theoretical ontological foundations of education from the standpoint of research education development. The task is definition and validation of a future education model that will make research education a subject of socio-economic modernization of the society. In this respect, the question is raised of an actual belonging of the modern research education, which has a distinctive scientistic character.

The purpose of the study - definition the fundamental characteristics of education in the knowledge society - is elaborated on the following key questions: (1) What is the characteristic of fundamental grounds of research education in the knowledge society? (2) What is the conceptual effect of the research education sector on education as such in the knowledge society? The theoretical forecast of the fundamental grounds of education in the knowledge society is the result of methodological synthesis of three lines of the research the author has been engaging in for the last ten years: ontology of education, knowledge society, and research education. As its experimental basis, the theoretical development uses practical activities in the Russian "Step into the Future" program.

The key role of research education in the knowledge society is shown and its socio-economic advancement at different levels of education is studied. Fundamental grounds for research education are identified as follows: attitude to the truth, scientific-type research behavior, cognition methods intrinsic to science, early involvement in research activities, scientific and educational continuity between school and university, institutional and cognitive diversity. The impact of the research education sector leads to formation of a sectored structure both in higher and secondary education, which is described by a paradigm-differentiated education model.
\end{abstract}

Keywords: Education, ontology, science, research, cognition.

How to cite: Karpov, A.O. (2018). Fundamentals of Education in Knowledge Society: Theoretical Forecast. Revista Romaneasca pentru Educatie Multidimensionala, 10(1), 171-182. https://doi.org/10.18662/rrem/27 


\section{Introduction}

The knowledge society conception is an influential paradigm of the present-day social development. Along with this fact, the very notion of "knowledge society" has different theoretical interpretations; it is often treated as a new socio-economic formation. I uphold another position that the knowledge society is a specific, dynamically developing socio-economic and cultural system inside the modern society. It organizes the society for the purpose of scientific production of knowledge, which are embodied in its social structure and transforms society by itself (Communities, 2003).

The knowledge society is treated primarily by me as a society of scientific knowledge, not information aggregates. This viewpoint is justified by a decisive productive role of scientific knowledge in the social, cultural, and economic development of the modern society. By scientific knowledge I have in mind the knowledge acquired as a result of science actions, which is codified in scientific sources, circulates in research teams and is part of scientific education. The best-known properties the knowledge (not information) possesses is an active quality of knowledge and its ability to generate new knowledge. This is exactly what the society analysis determines as the knowledge society.

Bearing socio-economic structures of the knowledge society began to take shape in the immediate post-war years; among them was a new system of labor division that came into existence together with a knowledge worker, as well as the fact that P. Drucker fixed in 1957 - an innovative system that included science, a pluralistic community of organizations; a society, where the basis of its development was education (Etzkowitz, 2008) (Bell, 1999). Bell points to powerful science-driven research universities, a strong entrepreneurial culture, and venture capital for small business financing as sources of technological leadership of the USA (Bell, 1999). By the beginning of the 20th century, a creative economy was formed, where creativity encouraged entrepreneurship, innovations, and economic growth (Curley \& Formica, 2015). At the same time, a creative class emerged, consisting of people who added economic value through their creativity (Heidegger, 1993). Instruments of material and spiritual growth of the society were becoming cognitive-type professions having a large volume of creative activities in the fields associated with science.

In 1953, Martin Heidegger in the "Science and Comprehension" report points to a fundamental change originating in ontological foundations of education. In his opinion, "the age of education is coming to end", i.e. 
education in its classical meaning, education that shapes a person based on standards and is based on prescriptions, sets a course for ending. Things are coming to the era of education, where a person must comprehend oneself by oneself(A. Karpov \& Pruzhinin, 2011).

By the end of the 20th century, science and technology became not just a man's destiny, but captured the very essence of man's life. In this historical perspective, the scientistic direction, despite its obvious human defectiveness, began to determine the ontological foundation and social action of education. And this reality today is stronger than desire of individuals and social groups to try other options for educational development.

It seems that a totally shaping role of science and technology in education makes very problematic the Heidegger's (Heidegger, 1993) project implementation. Not only because it is still based on the prescription. The character of this prescription is found as very important. Education, which prescribes to study a growing conglomerate of unrelated scientific facts, in its essence ceases to be scientific. It becomes a formal dogma, and its texts a catechism.

The criterion of the scientific character of education in the knowledge society is the use of cognition methods in the educational process which are inherent in scientific research. Education prescribing scientific-research cognition methods requires not only mastering a subject domain, but also gives a tool for comprehension oneself in it. Such a tool is a scientific inquiry, always involving the cultivation of one's own capacity for cognition discovering the world. Reflection of facts on the basis of a common cognition pattern deprives of this capacity.

The development of education is not separable from the development of society. The anthroposocial shift to total economic efficiency, implanted by political institutions in industrialized countries, is combined with a tremendous existential devastation of generations starting their life in the new century. As happened more than once before, being worried about humankind, we forget about a man.

At the same time, the knowledge society model, which justifies this anthroposocial shift, rests on productivity of human thinking and, above all, scientific-type thinking. With this substitution, an economic scientism model is generated, where a cognitive function of scientific thinking is regulated by monetary values. The attitude to the truth is deleted from the agenda of human life, and comprehension oneself as an individual which is centered on it - the basis of spiritual life and moral world, goes away together with it. This comprehension, taken from the standpoint of a personal mission in its 
cultural and historical context and perspective, reveals the place of individual belonging and vocation, i.e. talks about who a person is and what he/she is. It is this place the civil-mindedness arises from.

\section{Problem Statement}

Education can act as a subject of socio-economic modernization, if such future education model is identified and scientifically justified, that will allow it to play this role. Therefore, the question of actual belonging of the modern scientific education arises with particular acuteness; namely, about those who are subject to this education level, and how it relates to those who are not subject to.

\section{Research Questions}

As key research questions, I identify the following:

3.1 What is the characteristic of fundamental foundations of research education in the knowledge society?

3.2 What is the conceptual impact of the research education sector on education as such in the knowledge society?

\section{Purpose of Study}

The purpose of the study is definition of fundamental characteristics of the education evolution in the knowledge society.

\section{Research Methods}

The proposed theoretical forecast of the education fundamental foundations in the knowledge society is a result of synthesizing three directions of the study the author has been engaging in for the last ten years.

The first direction - the ontology of education, defines a methodological background for this research. Education is presented by me as a sociocultural phenomenon with fundamental characteristics analyzed in essential spaces. The universum space defines the contextual completeness of the description; it explicates the cultural, historical, social, anthropological, economic realities of education. The generative-constitutive space specifies a functionality of the description, i.e. whereby education acquires its existence - educational institutions, a system of personality training and upbringing. The ontogenic space sets a depth of description - education is based on in its being. Here we study universal and paradigmatic structures of education, fundamental structures of personality formation. For a fundamental 
description of the edcation phenomenon, the author developed an in-depth ontologization model and a non-Kuhnian theory of paradigms (A. O. Karpov, 2016).

The second direction - the knowledge society, gives in my research a visualization of a social future, into which the modern education is dipping into. The genesis of the knowledge society concept and its reality (beginning from 1940s) is studied, the meaning of the "knowledge worker" notion and its social role are identified, and a cognitive-role model of a social structure and education in the knowledge society is developed (A. O. Karpov, 2017).

The third direction - the research education, gives theoretical and experimental materials relevant to the culture-decisive system of education in the modern society, which trains a knowledge worker and forms an educational basis for the future society. The author not only developed a lot of new theoretical materials, but also carried out experimental studies in the scientific-educational space of the "Step into the Future" program. This program was created by me in Russia more than a quarter of a century ago. Today, every year more than 150 thousands of young researchers schoolchildren and students, take part in this program

\section{Findings}

\subsection{Characteristics of fundamental foundations of the research education in the knowledge society}

Education plays a decisive role in the knowledge society development because it is a part of a social system through which society reproduces and transforms itself. The society "working" on the basis of knowledge, as well as culture in which this society is developing, rests on cognitive abilities of a creative personality. Education, that fosters young people gifted in scientific creativity, i.e. research education, acts as a culturegenerating foundation of the knowledge society. This education includes priorities of social development and socio-cognitive growth of a person; it makes a person capable for creation of new knowledge, its technologization and inclusion in the life of society (Florida, 2002). In research education, a young person acts primarily as a subject of cognition, rather than an object of learning.

Research education brings up a scientific attitude to the truth and forms scientific-type research behavior. The main goal that guides a learner in research activities is a search for the truth, which leads to new knowledge. For a researcher, an attitude to the truth determines not only ethos and daily life principles, but it is a professional component in scientific work with 
knowledge that sets standards of cognitive behavior. Understanding the research as a search for the truth underpins scientific-type research behavior. It is driven by conscious search for the truth, which is embodied in scientific discoveries, engineering inventions, social innovations. In this way it differs from the innate psycho-biotic "curiosity" with roots in a primitive struggle for survival. This "curiosity" exhibits itself intuitively and irrespective of professional activities and a social role of an individual. Values of the research attitude to life a person develops by oneself, overcoming difficulties on the way toward the truth and upholding the truth.

By the end of the 20th century, scientific researches have become a genetic part of a special-type higher education with a mission that can be defined as education through scientific researches, rather than scientific researches and education (Stehr, 1994). Researches start their application as teaching methods; they shape the educational process and the creative function of thinking (Communities, 2003). At the beginning of the 20th century, universities assert themselves as a key element in building the knowledge society (Trow, 1968). At the political level, universities are declared as the basis of economic competitiveness. The idea of combining the scientific environments of universities plays a leading role in creation of excellence networks (Simons, 2006). There is a formation of university ecosystems resting on distributed creative environments (Communities, 2016). Universities become the center of concentration of creative thinking required for the processes of modernization and growth in prosperity of citizens.

The scientific-research approach to school education took its origin in the USA from late 1950s - early 1960s, that was associated with Soviet achievements in military and space technologies (Winch, 2004). In 1979, the report to the Club of Rome interprets education from generative views that are focused on an active role of a person in his/her attitudes to knowledge and society (Botkin, Elmandjra, \& Malitza, 1992). Special requirements are imposed on the school - it must develop skills of collective and individual work, capacities for critical appraisal and responding to new situations (Yazzie-Mintz 2007). In early 2000s, the problem to attract to schooling tasks the institutions specialized in functions performed by knowledge in the post-industrial culture is discussed in Western education (Carr, 2003). Scientific, professional and cultural institutions of the society are involved into the chain of educational institutions (A. O. Karpov, 2006).

In Russia, an emergence of scientific-research activities of schoolchildren was a result of the "Step into the Future" program - the nongovernmental and non-profit initiative of scientists, teachers and education 
professionals. The generative didactics cultivated by the program ensures a problem-cognitive growth of a learner together with a school teacher in conditions of the professional research environment (A. O Karpov, 2015). By so doing, the complex and joint development of basic and special competences is implemented on the basis of cognitive mobility in educational research-type networks.

The analyzed socio-historical dynamics in formation of a present-day research education sector makes it possible characterize in brief its fundamental foundations in the knowledge society.

Research education in the knowledge society is based on learning, which uses cognition methods inherent in science. It is aimed at formation of complex high-level competencies required for a knowledge worker to be started at the stage of school education. At the same time, early involvement of promising schoolchildren in scientific-research activities at the age of 1113 years is of key importance. Today, the very possibility of research university activities depends on the level of cognitive readiness of a schoolchild for acquiring the complicated systems of scientific knowledge. Research education should provide a link between education and research with innovative and scientific-entrepreneurial activities. The answer to this challenge should be a special educational system supporting the principle of scientific-cognitive continuity between a school and a university (as it is called by me). Its main components are: (1) cluster-network types of scientific and educational partnerships, (2) learning \& scientific innovation environment of the cognitive-generative type, (3) scientific research methods of cognition (A. O. Karpov, 2013).

Consequently, the system of research education in the knowledge society possesses a high level of institutional and cognitive diversity. It covers a research school and a research university (including an entrepreneurial type) that are linked by a scientific-cognitive continuity both at the level of environments and a learning method, as well as corporate training programs for researchers and developers. Its institutional basis is cluster-network partnerships with research institutions, high-tech companies, innovative development organizations. In this system, scientific researchers are a system-forming factor of the educational and cognitive process. It becomes the basis of global competitiveness of national economies and geopolitical unions, and its innovative \& entrepreneurial ecosystem generates new, rapidly developing industries, as well as promising technological markets, economically leading administrative-territorial spaces. 


\subsection{Conceptual impact of the research education sector on education in the knowledge society}

The epistemological foundation of education in the knowledge society is scientific-type productive thinking on the basis of human creativity. The research training method in its science-oriented implementation is designed for education of young people who are cognitively predisposed to work in spheres of scientific knowledge production, or in other words, group of technological progress. At the same time, the knowledge society as a socio-economic system is only a part of the modern society, and research education trains only a limited number of young participants.

However, we can not underestimate the total influence, which still can have a very minor socio-economic localization, designated as the "knowledge society", on the present-day culture, style of life and future of a person as a person. The idea of productive thinking taken as the basis of research education has an impact not only on the knowledge production sector. It cardinally raises the question of conditions in which the cogito of a growing personality will get a chance to maximum realization of a personal potential in certain spheres of human life, i.e. the question of cognitive belonging of an individual in general. As one of principles of social justice, it declares the distribution of people in the system of labor division according to their cognitive abilities and vocations.

It should be noted that the modern society reality in itself is unlikely capable to raise this question. For example, according to sociological studies, $26 \%$ of Americans and Europeans and $32 \%$ of Russians adhere to the idea that the Sun moves round the Earth. Western experts point to cultural backwardness of scientific education from cognitive conditions of the time, because scientific thinking is viewed today using a conceptual vocabulary of Bohr, Heisenberg and Prigogine, while curricula feel closer to the epistemic system of Descartes, Newton and Laplace (Drucker, 1996). The language of great compatriots - Landau, Sakharov and Prokhorov, is also alien to the mass Russian education system.

At the same time, cultural demands of the present-day world presuppose a certain scientific and research psyche of all successful members of the society. As shown by results of the Strata-Etan group, the competencies involved in research activities have a high degree of coincidence with competencies "for employment" on the modern labor market (Doll, 1993). Consequently, today, the problem of personality transformation to be solved by education as an institutionalized system of 
socialization has its own "research" dimension. Hence, the scientific research acquires a high didactic potential in the modern society.

However, it does not mean that research training, even in its easiest project version, is a recipe for all learners. Does it really mean that new Middle Ages are coming because of the presence of approx. 30\% of nonCopernican persons in the modern society, if most of the $70 \%$ who give a heliocentric answer to the question of the solar system kinematics cannot use this fact for explanation of such astronomical phenomena as eclipses and phases, alterations of seasons?

Scientism is formally adopted by the modern education system failing to develop a learning method that would make it possible to generate a scientific worldview at a practical level in the "scientised" society. I believe that today this problem has no solution. What does "research" dimension propose in the non-research education? First of all is the development of abilities for research "movement" of the mind on the basis of scientific facts. And not for the purpose of these facts collection, but for formation a special, "quasi-scientific" methodicalness of thinking within certain limits close to what the scientific method uses in thinking. This is a complicated pedagogical problem that can be approached, in my opinion, by cognitivecentered and creative learning methods that, to a large extent, exclude tests, contests, and projects as mass didactic tools.

This didactic approach will make it possible to keep the "cognitive face" of a future man of art, a humanities-minded person, a manager, an employee in other fields. In the meantime, the ubiquitous model of the official school in the industrial age acting as a translator of instructions causes not only inactivity of learners but also absolute inability to become a future member of the knowledge society. Thus, according to one the largest studies conducted in 26 states of the USA, almost $40 \%$ of respondents believe that subjects taught at school are not relevant for life, $45 \%$ do not feel themselves important participants of school communities, and only $2 \%$ say that they were never bored at school.

Using methods of building a "quasi-scientific" methodicalness of thinking, modern education will become an instrument of the research-type socialization, which trains young people for life in the knowledge society (A. O Karpov, 2015). This new type of socialization, first described by me, acquires a global social significance. It takes place in cognitively saturated environments that can motivate learners and be flexible for their diversified needs.

The knowledge society development calls for formation of a separate sector of research education covering a research university and a research 
school. For secondary education, this means that it is becoming nonuniversal. For the education system as such, this means the formation of a paradigm-differentiated education system, where any educational sector will function on the basis of its own local paradigm. The local paradigm defines a dominant type of cognitive activity, systems of significant educational situations and basic methods, normative and methodological declarations, structures of an educational organization and modes of an educational process.

The paradigm-differentiated education system can become a place of cognitive-cultural diversity generation, rather than a universal identity. Similar to biodiversity, which creates opportunities for realization of creative forces of nature, the cognitive-cultural diversity increases a creative productivity and a divergent potential of the society making progress through knowledge production. One of the primary functions of the paradigm-differentiated education system is the creation of psychically comfortable cognitive conditions for different cognitive types of personalities in their relevant socio-cultural environments.

The society, where productivity of scientific knowledge is the foundation for its existence and development, is objectively predisposed to creation of comfortable conditions for activity of human thinking, i.e. such conditions, in which its cognitive function and socially transforming role are implemented to the fullest extent. This social and educational constitution is named as the "cognitive-cultural polymorphism" (Karpov, 2013).

The implementation of the cognitive-cultural polymorphism principle in the education system presupposes: (1) a cognitively saturated educational environment containing the richness of cultural forms of social groups, including the ethnic diversity; (2) a system of cognitive methods that provides culturally comfortable cognitive actions; (3) their interaction that creates an effective basis for creativity as a culturally determinated phenomenon. The cognitive-cultural polymorphism of educational communities opens the way to a real and effective educational equality, because it makes productive the cognitive and socio-cultural uniqueness of learners.

\section{Conclusions}

Fundamental transformations of education foundations in conditions of the knowledge society development follow the Heidegger's project, which believes that the key function of education is comprehension of own social and existential essence by a growing personality. The main 
institutional actor creating conditions and stimulating this comprehension is the research education sector. Its influence leads to formation of a sectorally divided structure both in higher and secondary education, which can be described by a paradigm-differentiated education model. This type of education can ensure the individual cognitive development in line with a true vocation of a person.

\section{References}

Bell, D. (1999). The Axial Age of Technology Foreword. New York: Basic Books. P. .

Botkin, J. W., Elmandjra, M., \& Malitza, M. (1992). In No limits to Learning. Bridging the Human Gap. A Report to the Club of Rome.

Carr, D. (2003). Making Sense of Education. London and New York Routledge Falmer.

Communities, C. o. t. E. (2003). The Role of the Universities in the Europe of Knowledge. .

Communities, C. o. t. E. (2016). Delivering on the Modernization Agenda for Universities: Education, Research and Innovation. Brussels.

Curley, M., \& Formica, P. (2015). The Experimental Nature of New Venture Creation. New York: Springer Science\&Businnes Media.

Doll, W. E. (1993). A Post-modern Perspective on Curriculum. Teacher College Press, Columbia University, New York and London.

Drucker, P. F. (1996). Landmarks of Tomorrow. A Report on the New post-Modern World. Retrieved from N.Y.:

Etzkowitz, H. (2008). The Triple Helix: University - Industry - Government. Innovation in Action. N.Y. and London: Routledge.

Florida, R. L. (2002). The Rise Of The Creative Class N.Y.: Basic Books. Heidegger, M. (1993). Science and Comprehension Paper presented at the Articles and speeches.

Karpov, A., \& Pruzhinin, B. I. (2011). How Are We Going to Transform Education? . Russian Education and Society, 53(8).

Karpov, A. O. (2006). Pedagogy. . Cognitive-Cultural Polymorphism of Educational Systems., 3 13-21.

Karpov, A. O. (2013). Socio-Cognitive Structure \& Education in Knowledge Society Society and Economy., 11-12, 5-20.

Karpov, A. O. (2015). Integrated and network systems of research education in the knowledge society (by example of the Russian educational system). . Mediterranean Journal of Social Sciences. Rome: MCSER Publishing., 6(6), 529-540. 
Karpov, A. O. (2016). Generative Learning in Research Education for the Knowledge Society (Vol. 11).

Karpov, A. O. (2017). Early Engagement of Schoolchildren in Research Activities:

The Human Factor. Advances in Human Factors in Training, Education, and Learning Sciences. Basel: Springer International Publishing AG.

Simons, M. (2006). Education Through Research» at European Universities: Notes on the Orientation of Academic Research. Journal of Philosophy of Education. Oxford: Blackwell Publishing, 40(1), 31-50.

Stehr, N. (1994). Knowledge Societies. London Sage.

Trow, M. (1968). The Sociology of Education. N.Y., London: Basic Books.

Winch, C. (2004). Developing Critical Rationality as a Pedagogical Aim. Journal of Philosophy Education, 38(3), 467-484

Yazzie-Mintz, E. (2007). Voices of Students on Engagement: A Report on the 2006 High School Survey of Student Engagement. . Retrieved from Bloomington: 